\title{
Relationship between Autoimmunity and Cancer or Metabolic Abnormality in Liver Diseases
}

\author{
Takashi Himoto $^{1,2, *}$ Mikio Nishioka ${ }^{2,3}$ and Tsutomu Masaki ${ }^{2}$ \\ ${ }^{I}$ Department of Integrated Medicine, Japan \\ ${ }^{2}$ Department of Gastroenterology and Neurology, Japan \\ ${ }^{3}$ Emeritus Professor, Kagawa University School of Medicine, Kagawa 761-0793, Japan
}

\begin{abstract}
Recent advances in the serological analysis of recombinant cDNA expression libraries and proteomic analysis have enabled the identification of numerous kinds of novel autoantigens, especially tumor-associated antigens (TAAs). The emergence of antibodies to TAAs might imply that an autoimmune response was involved in the malignant transformation. These autoantibodies to TAAs often have predictive value as well as diagnostic relevance. Similarly, the relationship between autoimmunity and metabolic abnormalities, including insulin resistance and hepatic steatosis, has been also documented. Metabolic abnormalities are frequently associated with autoimmune diseases. In contrast, autoimmune reactions were occasionally involved in the process of metabolic dysregulation. This review primarily focuses on the current trends for the relationship between autoimmunity and cancer or metabolic abnormalities in liver disease and the current interpretations of autoantibodies in those diseases.
\end{abstract}

Keywords: Autoantibodies, cancer, liver diseases, metabolic abnormalities, oxidatively modified autoantigens, stress proteins, tumor-associated antigens.

\section{INTRODUCTION}

Autoantibodies are generally produced by humoral immune responses against self-cellular proteins and nucleic acids [1], and have been well established as serological hallmarks of autoimmune disease. Recent advances in the molecular technology using a recombinant cDNA expression library (serological identification of antigens by recombinant expression cloning: SEREX) have enabled the isolation of novel autoantigens from the sera of patients with autoimmune or malignant diseases. Some of these autoantibodies often have clinical value for the diagnosis, and classification of the autoimmune disease and its disease activity. Other autoantibodies can even predict the prognosis of the autoimmune diseases and malignant diseases. Such autoantigens are ordinarily engaged in essential cellular functions including DNA replication, DNA transcription, and RNA processing [2].

The detection of autoantibodies is essential in the process of diagnosing autoimmune liver diseases, including autoimmune hepatitis (AIH), primary biliary cirrhosis (PBC) or primary sclerosing cholangitis (PSC). However, some of these autoantibodies are occasionally present even in the sera of patients with liver disease other than autoimmune liver diseases [3-7]. Such autoantibodies can be detected in the sera of patients with viral hepatitis, alcoholic liver disease,

*Address correspondence to this author at the Department of Integrated Medicine, Kagawa University School of Medicine, 1750-1, Ikenobe, MikiCho, Kita-Gun, Kagawa 761-0793, Japan; Tel: +81-87-891-2349;

Fax:+81-87-864-4631; E-mail: thimoto@med.kagawa-u.ac.jp non-alcoholic fatty liver disease (NAFLD), drug-induced hepatitis, and hepatocellular carcinoma (HCC).

On the other hand, the relationship between autoimmunity and insulin resistance has been widely studied [8]. Patients with systemic lupus erythematosus (SLE) are often associated with metabolic syndrome $[9,10]$. In addition, a recent article described the relationship between thyroid autoantibodies and obesity [11]. These findings may imply that the metabolic abnormalities trigger the production of a variety of autoantibodies.

This review mainly discusses the current trends of the relationship between autoimmunity and cancer or metabolic abnormalities in the liver diseases, and describes the interpretation of autoantibodies in those liver diseases.

\section{AUTOANTIBODIES IN THE SERA OF PATIENTS WITH HEPATOCELLULAR CARCINOMA}

\section{1) Methods for the Detection of Antibodies to Tumor- Associated Antigens}

It has been well established that patients with autoimmune disease including Sjögren's syndrome are frequently complicated with the development of lymphoproliferative disorders, especially non-Hodgikin's lymphoma [12]. Inversely, autoimmune response is occasionally observed in cancer patients during the process of malignant transformation [13]. The autoantibodies detected in cancer patients are directed against nuclear antigens, against cytoplasmic antigens, and even against extracellular antigens. 
HCC has been well recognized as one of the most common malignant tumors in the world with a high mortality. HCC has a clinical characteristic that develops from precursor conditions such as chronic hepatitis or liver cirrhosis [14]. Imai and colleagues documented that antinuclear antibodies (ANA) emerged de novo or the titers of ANA had been increased during the development of HCC from the precursor conditions [15]. These findings may support the hypothesis that an autoimmune response is involved in the process of malignant transformation.

Numerous types of autoantibodies to tumor-associated antigens (TAAs) have been identified in the sera of cancer patients. TAAs primarily consist of membrane receptors such as HER-2/neu oncoprotein [16], tumor suppressor gene proteins like p53 [17], proliferation-associated antigens includ- ing cyclin B1 [18] and centromere protein F (CENP-F) [19], and onconeural proteins such as $\mathrm{Hu}$ [20]. Table 1 summarizes the autoantibodies to TAAs identified from patients with HCC [18,19, 21-41]. Isolation of several kinds of TAAs has been accomplished using the recombinant cDNA expression library called serological identification of antigens by recombinant expression cloning (SEREX) [42]. Later, a method of serological proteome analysis (SERPA) (also called PROTEOMEX) has been proposed to trap autoantibodies to TAAs [43]. This approach is mainly based on a classical proteomics workflow combining effective separation on 2dimensional gel electrophoresis and identification by mass spectrometry. More recently, proteosome-covered array chips have been introduced as a novel technique for the detection of TAAs [44].

\section{Table 1 Clinical significance of autoantibodies to TAAs in patients with HCC.}

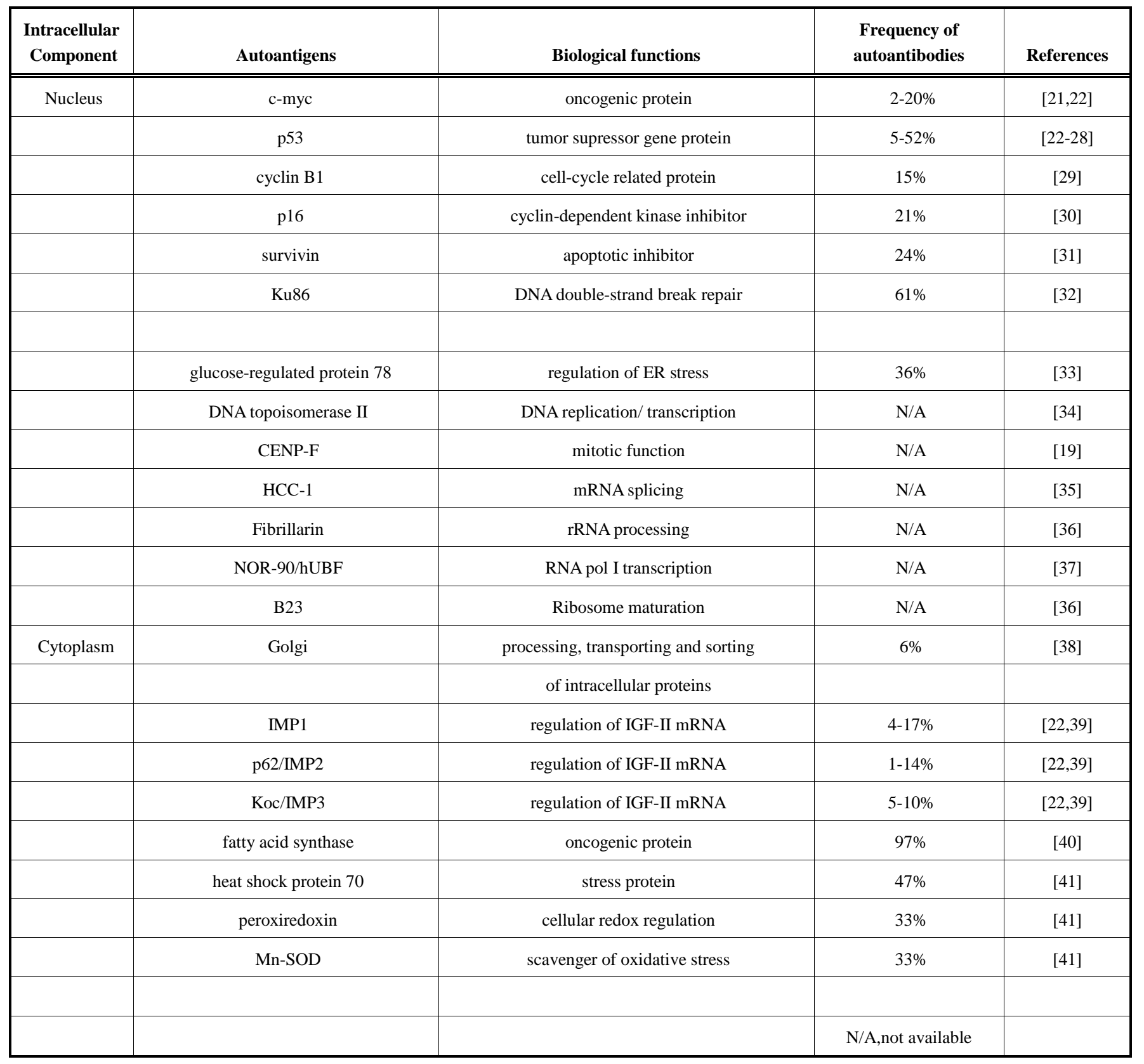


2) Putative Mechanism by which Autoantibodies to TAAs are Produced

Among these anti-TAAs, antibodies to p53 have been the most widely studied. The putative mechanism by which the autoantibodies are produced is as follows: the gene mutation of $\mathrm{p} 53$ causes an increase in the half-life of p53, leading to the accumulation of non-functional 153 protein in the nucleus of tumor cells. The accumulated p53 proteins are likely to become immunogenic, and subsequently evoke a humoral response to the p53 protein [17]. Similarly, antibodies to Kras are present in approximately $20 \%$ of patients with esophageal carcinoma [45]. The production of antibodies to K-ras may also derive from the mutation of the K-ras gene [46]. Unfortunately, there is no study regarding antibodies to K-ras in patients with $\mathrm{HCC}$ so far.

We previously investigated the clinical significance of autoantibodies to IGF-II $\underline{m R N A-b i n d i n g ~ p r o t e i n s ~(a n t i-~}$ IMPs) in patients with HCC. The HCC patients with circulating anti-IMPs have overexpression of IMPs in the tumor cells, supporting the hypothesis that these autoantibodies are produced by an antigen-driven immune system [38].

It has been recently documented that gene promoter methylation plays important roles in the regulation of gene expression. Aberrant promoter methylation of the genes can directly lead to transcriptional inactivation and loss of gene function [47]. The methylation of tumor-associated genes may be involved in carcinogenesis [48-50] and may trigger the production of autoantibodies to TAAs (anti-TAAs).

\section{3) Diagnostic Significance of Anti-TAAs}

In general, the sensitivities of anti-TAAs in patients with HCC are comparatively low, although their specificities seem to be extremely high. For example, the sensitivities of antibodies to p53 (anti-p53) in patients with HCC ranged from $5-52 \%$, while their specificities ranged $96-100 \%$ in those patients [22-28]. It is notable that the status of anti-p53 appears to be independent of the elevation of serum $\alpha$ fetoprotein (AFP) levels, the tumor marker for HCC [23].

Recently, an enzyme-linked immunosorbent assay (ELISA) technique for the detection of antibodies to CENPF was developed by Welner and colleagues [51]. They used overlapping synthetic peptides covering the predicted structural maintenance of chromosomes (SMC) domain. Half of the patients seropositive for anti-CENP-F were diagnosed with cancer using the ELISA method.

We previously examined the frequency of anti-TAAs, including anti-p53, c-myc, survivin and IMPs, in patients with HCC. Eight of $86(9 \%)$ patients with HCC had one or more of these autoantibodies [21]. However, the levels of serum AFP in 7 of those 8 patients with anti-TAAs remained within normal limits, indicating that anti-TAAs are complementary tools for the diagnosis of HCC in those patients without elevation of AFP levels.

Interestingly, Akada and colleagues isolated antibodies to heat shock protein (HSP) 70 from the sera of patients with
HCV-related HCC alone, implying that persistent HCV infection may induce a tumor-associated antigen during malignant transformation [44]. Recently, glucose-regulated protein 78 (GRP78), which is a chaperone protein belonging to the HSP70 family, was captured as a novel TAA in patients with HCC [32]. Fatty acid synthase was also identified as a novel TAA from those patients [39]. It is of interest that these TAAs are the proteins which originally contribute to glucose and lipid metabolism, respectively, implying that the metabolic dysregulation may evoke an autoimmune response during malignant transformation. Unfortunately, the clinical significance of these antibodies to HSP70, GRP78 and fatty acid synthase remains uncertain. Further examinations will be required to clarify it.

\section{4) Predictive Values of Anti-TAAs}

A previous study documented that HCC patients with anti-p53 seemed to predict an unfavorable prognosis [26]. In, addition, an association between the emergence of anticentromere antibodies (ACA) and malignancy has been shown. ACA may be a risk factor for cancer in patients with systemic sclerosis [52]. We previously elucidated that ACA were rarely found in the sera of patients with HCV-related chronic liver disease (CLD) [53] as well as those with AIH and PBC [54], and that patients with HCV-related CLD seropositive for ACA often progressed to HCC [53].

On the other hand, we experienced a HCC patient who had circulating anti-p53, anti-IMP1 and anti-IMP3 simultaneously prior to the clinical diagnosis of HCC, suggesting that the emergence of these autoantibodies may predict the development of HCC [21].

\section{5) Anti-p53 in Autoimmune Liver Disease}

Anti-p53 are sometimes present in the sera of patients with autoimmune diseases such as SLE [55], rheumatoid arthritis [56] and dermatomyositis/polymyositis [57]. It is of interest that the emergence of anti-p53 was not found to be associated with the mutation of p53 gene in patients with SLE [55].

Anti-p53 is considered to be useful to discriminate patients with AIH from those with PBC [58, 59]. The prevalence and titers of circulating anti-p53 were significantly higher in patients with AIH than in those with PBC. Cellmediated cytotoxicity is involved in the pathogenesis of $\mathrm{AIH}$, while liver damage in patients with $\mathrm{PBC}$ is primarily caused by cholestasis. The existence of anti-p53 is likely to correspond to a secondary hallmark for autoimmune inflammation and stress. Taking these findings into consideration, the lower frequency of anti-p53 in the sera of patients with PBC can be explained.

It is remarkable that circulating anti-p53 detected in patients with $\mathrm{AIH}$ were predominantly directed against the Cterminal domain of p53 protein [58]. Moreover, the titers of anti-p53 in patients with AIH were significantly associated with the titers of antibodies to ds-DNA [59], suggesting that DNA damage may trigger the production of anti-p53. 
AUTOANTIBODIES IN SERA OF PATIENTS WITH LIVER DISEASE ASSOCIATED WITH METABOLIC ABNORMALITIES

1) Relationship between Autoimmunity and Metabolic Abnormalities in Liver Diseases

In the field of autoimmune liver disease, insulin resistance is commonly observed in patients with AIH [60] and PBC [61]. The phenomena may explain that insulin resistance contributes to the development of autoimmune liver disease. Meanwhile, approximately $20-30 \%$ of patients with NAFLD, which is characterized by obesity, insulin resistance and other excessive nutritional intake, had ANA in their sera, suggesting that the autoimmune response might be involved in the process of insulin resistance [62-65]. The elevation of serum B-lymphocyte activating factor (BAFF) levels in patients with nonalcoholic steatohepatitis (NASH) may be attributed to insulin resistance [66].

Oxidative stress also plays crucial roles in the metabolic abnormalities including insulin resistance, hepatic steatosis, and iron overload [67, 68]. Oxidation of the host proteins appears to be responsible for the humoral response to the host proteins. Indeed, oxidatively modified autoantigens, including oxidized low-density lipoprotein (oxLDL), 4hydroxy-2-noneal (HNE)-modified $60 \mathrm{kD}$ Ro and 8- oxodeoxyguanine, were identified from patients with SLE as novel autoantigens [69].

Recent studies have revealed that oxidative modification of self-antigens may initiate a process of oxidative posttranslational modification intolerance, resulting in a primary B cell response against the posttranslationally modified selfantigen. Moreover, a secondary response may involve the development of autoreactive B cells by way of "epitope spreading", which is defined as the progression of an autoimmune response from initial activation to a chronic state involving increased targeting of autoantigens by $\mathrm{T}$ cells and antibodies [70].

\section{2) Clinical Significance of Autoimmunity in Liver Diseas- es Associated with Metabolic Abnormalities}

A recent study focused on the relationship between ANA status and insulin resistance in patients with NAFLD. Loria and colleagues documented that the high titers of ANA may be an indicator for a severe insulin resistance in those patients [71].

Here, autoantibodies to stress proteins in the field of liver diseases and their significance are summarized in Table $\mathbf{2}$. Antibodies to oxidatively modified autoantigens were also trapped in the sera of patients with NAFLD and chronic hepatitis $\mathrm{C}(\mathrm{CH}-\mathrm{C})$. Titers of malondialdehyde (MDA)-adducted

Table 2. Clinical significance of autoantibodies to stress proteins in liver diseases

\begin{tabular}{|c|c|c|c|c|}
\hline Autoantibodies & Molecular Target & Associated Liver Disease & Clinical Significance & References \\
\hline anti-MDA & MDA & $\mathrm{HCV}$ & correlation with hepatic steatosis & [72] \\
\hline anti-oxLDL & oxLDL & $\mathrm{HCV}$ & correlation with hepatic steatosis & [75] \\
\hline anti-SOD & SOD & $\mathrm{AIH}$ & false-positivity for anti-HCV & [78] \\
\hline \multirow{5}{*}{ anti-cardiolipin } & & $\mathrm{HCV}$ & higher prevalence of portal hypertension & [86] \\
\hline & & $\mathrm{HCV}$ & lack in the symptoms for anti-phospholipid syndrome & {$[79,81-84]$} \\
\hline & & $\mathrm{HCV}$ & concurrent oral lichen planus & {$[87]$} \\
\hline & & $\mathrm{HCV}$ & concurrent mixed cryoglobulin & [88] \\
\hline & & PBC, PSC & indicator for more advanced liver fibrosis & {$[90]$} \\
\hline \multirow[t]{4}{*}{ anti-CYP2E1 } & CYP2E1 & halothene-induced hepatitis & specific to IgG4 type of anti-CYP2E1 & {$[101]$} \\
\hline & & alcoholic liver cirrhosis & N/A & {$[95,96]$} \\
\hline & & $\mathrm{AIH}$ & N/A & [97-99] \\
\hline & & $\mathrm{HCV}$ & indicator for more severe necroinflammation & {$[97,102]$} \\
\hline \multirow[t]{2}{*}{ anti-HSP } & HSP65 & AIH & molecular mimicry between HSP and SOD & {$[105]$} \\
\hline & HSP70 & PBC & indicator for disease activity & {$[106]$} \\
\hline
\end{tabular}


human serum albumin (HSA) were elevated in $\mathrm{CH}-\mathrm{C}$ patients with severe hepatic steatosis [72]. To the contrary, an increase in titers of antibodies to MDA-HSA was independently associated with the progression of liver fibrosis in patients with NAFLD [73]. We previously elucidated that serum oxLDL concentration was significantly higher in patients with HCV-related CLD than in normal healthy controls [74] and that the titers of antibodies to oxLDL were significantly associated with the extent of hepatic steatosis in those patients [75]. However, the titers of antibodies to oxLDL were independent of insulin resistance in those patients. In contrast, antibodies to oxLDL were closely related to atherosclerosis in patients with rheumatoid arthritis [76]. Atherosclerosis has been considered one of the metabolic abnormalities caused by HCV infection [77]. Therefore, the emergence of antibodies to oxLDL may predict atherosclerosis in patients with $\mathrm{CH}-\mathrm{C}$. Further examinations are required to clarify the association.

An interesting study on the relationship antibody to superoxide dismutase (SOD) and anti-HCV in patients with AIH was previously reported by Ikeda and colleagues [78]. They revealed that the titers of anti-HCV were closely linked to the titers of antibodies to SOD in those patients, suggesting that antibodies to SOD may account for the false-positive result of anti-HCV status in those patients.

On the other hand, our previous study elucidated that the titers of antibodies to cardiolipin (anti-cardiolipin), the serological hallmark for anti-phospholipid syndrome, were associated with the extent of hepatic 8-hydroxy-2'-deoxyguanosine (8-OHdG) expression in patients with $\mathrm{CH}-\mathrm{C}$ [79]. $8 \mathrm{OHdG}$ is well recognized as oxidatively generated DNA damage [80], implying that the emergence of anti-cardiolipin was associated with oxidative stress in those patients. However, none of the $\mathrm{CH}-\mathrm{C}$ patients seropositive for anticardiolipin fulfilled the category for anti-phospholipid syndrome [79, 81-84]. It is of interest that anti-cardiolipin in patients with $\mathrm{CH}-\mathrm{C}$ were in generally low titers, and were not associated with antibodies to $\beta 2$-glycoprotein-I. Crossreactivity between $\mathrm{HCV}$ antigen and phospholipid is speculated to trigger the production of anti-cardiolipin. Persistent $\mathrm{HCV}$ infection may disrupt cell membrane and favor the exposure of hidden phospholipids [85]. Patients with HCVrelated CLD seropositive for anti-cardiolipin had a trend toward portal hypertension [86] or advanced hepatic fibrosis [79]. Anti-cardiolipin may be also indicative for concurrent oral lichen planus [87] and mixed cryoglobulinemia [88] in $\mathrm{CH}-\mathrm{C}$ patients, although the findings remain controversial [79].

Anti-cardiolipin were also found in the sera of patients with autoimmune liver disease including AIH, PBC and PSC $[89,90]$. Similarly, those patients with anti-cardiolipin had a higher prevalence of liver cirrhosis than those patients without anti-cardiolipin.

In addition, cytochrome p450 2E1 (CYP2E1) is an endoplasmic monooxygenase and major source of oxidative stress in microsomes [91]. Overexpression of CYP2E1 in the liver tissues is frequently observed in patients with NASH [92] and $\mathrm{CH}-\mathrm{C}$ [93]. Interestingly, the hepatic CYP2E1 expression was related to the severity of hepatic steatosis in patients with $\mathrm{CH}-\mathrm{C}$ [93]. In contrast, circulating antibodies to CYP2E1 were originally detected in the sera of patients with halothane-induced hepatitis [94] and alcoholic liver cirrhosis [95, 96]. Recently, CYP2E1 was also identified as a target antigen from patients with AIH [97-99], while CYP2D6 has been well recognized as the target antigen of antibodies to liver-kidney microsome type 1 (anti-LKM1) [100]. More recently, Njoku and colleagues revealed that the IgG4 type of antibodies to CYP2E1 was specific to the patients with anesthetic-induced hepatitis [101]. On the other hand, approximately $5-40 \%$ of patients with $\mathrm{CH}-\mathrm{C}$ possessed circulating antibodies to CYP2E1 in their sera $[97,102]$. The molecular mimicry between HCV NS5 and CYP2E1 may initiate the humoral response to CYP2E1 in those patients [103]. CH-C patients with circulating antibodies to CYP2E1 had more severe necroinflammation in the liver than $\mathrm{CH}-\mathrm{C}$ patients without antibodies to CYP2E1 [102], as usually did CH-C patients seropositive for ANA [104].

The HSPs, a family of ubiquitous and highly conserved proteins which play essential roles as molecular chaperones, appear to be antigenic. Antibodies to HSP65 detected in patients with AIH had cross-reactivity against SOD [105]. In contrast, antibodies to HSP 70 (anti-HSP 70) were found the sera of patients with PBC [106] and CH-C [107, 108]. AntiHSP 70 seemed to reflect the disease activity in patients with PBC, while the titers of anti-HSP 70 were inversely associated with serum alanine aminotransferase (ALT) levels and the loads of HCV-RNA in patients with CH-C [108].

\section{CONCLUSION}

In summary, autoimmune response is involved in the process of malignant transformation and metabolic dysregulation. Some types of autoantibodies to TAAs seem to be useful as a complementally diagnostic marker or predictive marker of HCC development. Other types of autoantibodies to stress proteins frequently reflect the severity of metabolic dysregulation and oxidative stress in the liver diseases.

\section{CONFLICT OF INTEREST}

The authors have no conflict of interest to declare.

\section{ACKNOWLEDGEMENT}

Declared none.

\section{REFERENCES}

[1] Tan EM. Antinuclear antibodies: diagnostic markers for autoimmune disease and probes for cell biology. Adv Immunol 1989; 44: 93-151.

[2] Tan EM. Autoantibodies in pathology and cell biology. Cell 1991; 67: 841-2.

[3] Czaja AJ, Homburger HA. Autoantibodies in liver disease. Gastroenterology 2001; 120: 239-49.

[4] Invernizzi P, Llel A, Podda M. Interpreting serological tests in diagnosing autoimmune liver diseases. Semin Liver Dis 2007; 27: 161-72.

[5] Zeman MV, Hirschfield GH. Autoantibodies and liver disease: uses and abuses. Can J Gastroenterol 2010; 24: 225-31.

[6] Zachou K, Rigopoulou E, Dalekos GN. Autoantibodies and autoantigens in autoimmune hepatitis: important tools in clinical practice and to study pathogenesis of the disease. J Autoimmune Dis 2004; 1: 1-17. 
[7] Himoto T, Nishioka M. Autoantibodies in liver disease: importamt clues for the diagnosis, disease activity and prognosis. Autoimmun Highlights 2013; 4: 39-53.

[8] Winer DA, Winer S, Shen L, et al. B cell promotes insulin resistance through modulation of T cells and production of pathogenic IgG antibodies. Nat Med 2011; 17: 610-17.

[9] Tso TK, Huang HY, Chang CK, et al. Clinical evaluation of insulin resistance and $\beta$-cell function by the homeostasis model assessment in patients with systemic lupus erythematosus. Clin Rheumatol 2004; 23: 416-20.

[10] El Magadmi M, Ahmad Y, Turkie W, et al. Hyperinsulinemia, insulin resistance, and circulating oxidized low density lipoprotein in women with systemic lupus erythematosus. J Rheumatol 2006; 33 : $50-6$

[11] Tamer G, Mert M, Termer I, et al. Effect of thyroid autoimmunity on abnormal obesity and hyperlipidemia. Endokrynol Pol 2011; 6: 421-8.

[12] Routsias JG, Goules JD, Charalampakis G, et al. Malignant lymphoma in primary Sjögren's syndrome: an update on the pathogenesis and treatment. Semin Arthritis Rheum 2013; 43: 178-86.

[13] Tan EM. Autoantibodies as reporters identifying aberrant cellular mechanisms in tumorogenesis. J Clin Invest 2001; 108: 1411-5

[14] Okuda K. Hepatocellular carcinoma. J Hepatol 2000; 32(Suppl 1): 225-37.

[15] Imai H, Nakano Y, Kiyosawa K, et al. Increasing titers and changing specificities of antinuclear antibodies in patients with chronic liver disease who develop hepatocellular carcinoma. Cancer 1993; 71: 26-35

[16] Lauterlein JJ, Petersen ER, Olsen DA, et al. Quantification of HER2 autoantibodies in amplification phenomenon of HER2 in breast cancer. Clin Chem Lab Med 2011; 49: 877-83.

[17] Soussi T. p53 antibodies in the sera of patients with various types of cancer.: a review . Cancer Res 2001; 60: 1777-88.

[18] Covini G, Chan EKL, Nishioka M, et al. Immune response to cyclin B1 in hepatocellular carcinoma. Hepatology 1997; 25: 75-80.

[19] Casiano CA, Humbell RL, Peeble C, et al. Autoimmunity to the cell cycle dependent centromere protein p330d/CENPF in disorder associated with cell prolification. J Autoimmun 1995; 8: 575-586

[20] Benyahia B, Liblau R, Merle-Beral H, et al. Cell mediated autoimmunity in paraneoplastic neurological syndrome with anti-Hu antibodies. Ann Neurol 1999; 45: 162-7.

[21] Himoto T, Kuriyama S, Zhang JY, et al. Analyses of autoantibodies against tumor-associated antigens in patients with hepatocellular carcinoma. Int J Oncol 2005; 27; 1079-85.

[22] Zhang JY, Megliorino R, Peng XX, et al. Antibody detection using tumor associated antigen mini-array in immunodiagnosing human hepatocellular carcinoma. J Hepatol 2007; 46: 107-14

[23] Volkmann M, Müller M, Hofmann WJ, et al. The humoral immune response to $\mathrm{p} 53$ in patients with hepatocellular carcinoma is specific for malignancy and independent of the $\alpha$-fetoprotein status. Hepatology 1993; 18: 559-65.

[24] Raedle J, Roth WK Roth, Oremek G, et al. a-fetoprotein and p53 autoantibodies in patients with chronic hepatitis C. Dig Dis Sci 1995; 40: 2587-94.

[25] Ryder SD, Rizzi PM, Volkmann M, et al. Use of specific ELISA for the detection of antibodies directed against p53 protein in patients with hepatocellular carcinoma. J Clin Pathol 1996; 49: 295-99.

[26] Shiota G, Kishimoto Y, Suyama A, et al. Prognostic significance of serum anti-p53 antibody in patients with hepatocellular carcinoma. J Hepatol 1997; 27: 661-68.

[27] Raedle J, Oremek G, Truschnowitsch M, et al. Clinical evaluation of autoantibodies to p53 protein in patients with chronic liver disease and hepatocellular carcinoma. Eur J Cancer 1998; 34: 1198203.

[28] Charuruks N, Tangkivanich P, Voravud N, et al. Clinical significance of p53 antigen and anti-p53 antibodies in the sera of hepatocellular carcinoma patients . J Gastroenterol 2001; 36: 830-36.

[29] Covini G, Chan EKL, Nishioka M, et al. Immune response to cyclin B1 in hepatocellular carcinoma. Hepatology 1997; 25: 75-80.

[30] Looi K, Megliorino R, Shi FD, et al. Humoral immune response to p16, a cyclin-dependent kinase inhibitor in human malignancies. Oncol Rep 2006; 16: 1105-10.

[31] Yagihashi A, Asanuma K, Kobayashi D, et al. Autoantibodies to surviving in patients with chronic hepatitis and hepatocellular carcinoma. Autoimmunity 2005; 38: 445-8.
[32] Nomura F, Sogawa K, Noda K, et al. Serum anti-Ku86 is a potential biomarker for early detection of hepatitis C-virus-related hepatocellular carcinoma. Biochem Biophys Res Commun 2012; 421 : 837-43.

[33] Shao Q, Ren P, Li Y, et al. Autoantibodies against glucoseregulated protein 78 as serological diagnostic biomerkers in hepatocellular carcinoma. Int J Oncol 2012; 41: 1061-67.

[34] Imai H, Furuta K, Landberg G, et al. Autoantibody to DNA topomerase II in primary liver cancer. Clin Cancer Res 1995; 1: 417-24.

[35] Imai H, Chan EKL, Kiyosawa K, et al. Novel nuclear autoantigen with splicing factor motifs identified with antibody from hepatocellular carcinoma. J Clin Invest 1993; 92: 2419-26.

[36] Imai H, Ochs RL, Kiyosawa K, et al. Nucleolar antigens and autoantibodies in hepatocellular carcinoma and other malignancies. Am J Pathol 1992; 140: 859-70.

[37] Chan EKL, Imai H, Hamel JC, Tan EM. Human autoantibody to RNA polymerase I transcription factor hUBF: molecular identity of nucleolus organizer region autoantigen NOR-90 and ribosomal RNA transcription upstream binding factor. J Exp Med 1991; 174: 1239-44.

[38] Mozo L, Simo A, Suarez A, et al. Autoantibodies to Golgi proteins in hepatocellualr carcinoma: case report and literature review. Eur J Gastroenterol Hepatol 2002; 14: 771-4.

[39] Himoto T, Kuriyama S, Zhang JY, et al. Significance of autoantibodies against insulin-like growth factor II mRNA-binding proteins in patients with hepatocellular carcinoma. Int J Oncol 2005; 26: 311-7.

[40] Heo CK, Woo MK, Yu DY, et al. Identification of autantibody against fatty acid synthase in hepatocellular carcinoma mouse model and its application to diagnosis of HCC. Int J Oncol 2010; 36: 1453-9.

[41] Takashima M, Kuramitsu Y, Yokoyama Y, et al. Proteomic analysis of autoantibodies in patients with hepatocellular carcinoma. J Proteomics 2006; 6: 3894-900.

[42] Sahin U, Tureci O, Pfreundschuh M. Serological identification of human tumor antigens. Curr Opin Immunol 1997; 9: 709-16.

[43] Caron M, Choquet-Kastylevsky G, Joubert-Caron R. Cancer Immunomics using autoantibody signatures for biomarker discovery. Mol Cell Proteomics 2007; 6: 1115-22.

[44] Akada J, Kamei S, Ito A, et al. A new type of protein chip to detect hepatocellular carcinoma-related autoimmune antibodies in the sera of hepatitis C virus-positive patients. Proteome Sci 2013, Epub.

[45] Blanchard P, Quero L, Pacault V, et al. Prognostic significance of anti-p53 and anti-KRas circulating antibodies in esophageal cancer. BMC cancer 2012; 12: [Epub. Ahead of Print].

[46] Lievrc A, Bachet JB, Boige V, et al. KRAS mutations as an independent prognostic factor in patients with advanced colorectal cancer treated with cetuximab. J Clin Oncol 2008; 26: 374-9.

[47] Zhang C, Li H, Zhou G, et al. Transcriptional silencing of the TMS1/ASC tumor suppressor gene by an epigenetic mechanism in hepatocellular carcinoma cells. J Pathol 2007; 212: 134-42.

[48] Chang H, Yi B, Li L, et al. Methylation of tumor-associated genes in tissue and plasma samples from liver disease patients. Exp Mol Pathol 2008; 85: 96-100.

[49] Lyer P, Zekri AR, Hung CW, et al. Concordance of DNA methylation pattern in plasma and tumor DNA of Egyptian hepatocellular carcinoma patients. Exp Mol Pathol 2010; 88: 107-11.

[50] Kim KM, Song MH, Kim MJ, et al. A novel cancer/testis antigen KP-OVA-52 identified by SEREX in human ovarian cancer is regulated by DNA methylation. Int J Oncol 2012; 41: 1139-47.

[51] Welner S, Trier NH, Frisch M, et al. Correlation between centromere protein-F autoantibodies and cancer analyzed by enzymelinked immunosorbent assay. Mol Cancer 2013, [Epub. Ahead of Print].

[52] Higuchi M, Horiuchi T, Ishibashi N, et al. Anticentromere antibody as a risk factor for cancer in patients with systemic sclerosis. Clin Rheumatol 2000; 19: 123-6.

[53] Himoto T, Nakai S, Kinekawa F, et al. Clinical characteristics of patients with hepatitis $\mathrm{C}$ virus-related chronic liver disease seropositive for anticentromere antibody. Dig Dis Sci 2009; 54: 360-8.

[54] Himoto T, Murota M, Yoneyama H, et al. Clinical characteristics of patients with autoimmune hepatitis seropositive for anticentromere antibody. Hepatol Res 2010; 40: 786-92 
[55] Kovas B, Patel A, Hershey JN, et al. Antibodies against p53 in sera from patients with systemic lupus erythematosus and other rheumatic diseases. Arthritis Rheum 1997; 40: 980-5.

[56] Mariette X, Sibilia J, Delaforge C, et al Anti-p53 antibodies are rarely detected in serum of patients with rheumatoid arthritis and Sjögren's syndrome. J Rheum 1999; 26: 1672-5.

[57] Miura Y, Yazawa N, Tamaki Z, et al. Anti-p53 antibodies in patients with dermatomyositis/polymyositis. Clin Rheumatol 2007; 26: $1328-31$.

[58] Herkel J, Modrow JP, Bamberger S, et al. Prevalence of autoantibodies to p53 protein in autoimmune hepatitis. Autoimmunity 2002; 35: 493-6.

[59] Himoto T, Yoneyama H, Kurokohchi K, et al. Clinical significance of autoantibodies to $\mathrm{p} 53$ protein in patients with autoimmune liver diseases. Can J Gastroenterol 2012; 26: 125-9.

[60] Durazzo M, Niro G, Premoli A, et al. Type 1 autoimmune hepatitis and adipokines: new markers for activity and disease progression? J Gastroenterol 2009; 44: 476-82.

[61] Himoto T, Yoneyama H, Kurokohchi K, et al. Contribution of zinc deficiency to insulin resistance in patients with primary biliary cirrhosis. Biol Trace Elem Res 2011; 144: 133-42.

[62] Yatsuji S, Hashimoto E, Kaneda H, et al. Diagnosing autoimmune hepatitis in nonalcoholic fatty liver disease: is the international autoimmune hepatitis group scoring system useful? J Gastroenterol 2005; 40: 1130-38.

[63] Adam LA, Lindor KD, Angulo P. The prevalence of autoantibodies and autoimmune hepatitis in patients with nonalcoholic fatty liver disease. Am J Gastroenterol 2004; 99: 1316-20.

[64] Cotler SJ, Kanji K, Keshavarzian A, et al. Prevalence and significance of autoantibodies in patients with non-alcoholic steatohepatitis. J Clin Gastroenterol 2004; 38: 801-4.

[65] Vuppalanchi R, Gould RJ, Wilson LA, et al. Clinical significance of serum autoantibodies in patients with NAFLD: results from the nonalcoholic steatohepatitis clinical research network. Hepatol Int 2011, Epub ahead of print.

[66] Miyake T, Abe M, Tokumoto Y, et al. B cell-activating factor is associated with the histological severity of nonalcoholic fatty liver disease. Hepatol Int 2012; Epub.

[67] Koike K. Miyoshi H. Oxidative stress and hepatitis C virus infection. Hepatol Res 2006; 34: 65-73.

[68] Browning JD, Horton JD. Molecular mediators of hepatic steatosis and liver injury. J Clin Invest 2004; 114: 147-52.

[69] Kurien BT, Scofield RH. Autoimmunity and oxidatively modified autoantigens. Autoimmun Rev 2008; 7: 567-73.

[70] Eggleton P, Nissim A, Ryan BJ, et al. Detection and isolation of human serum autoantibodies that recognize oxidatively modified autoantigens. Free Radic Biol Med 2013; 57: 79-91.

[71] Loria P, Lonardo A, Leonardi F, et al. Non-organ-specific autoantibodies in nonalcoholic fatty liver disease: prevalence and correlates. Dig Dis Sci 2003; 48: 2173-81.

[72] Vidali M, Tripodi MF, Ivaldi A, et al. Interplay between oxidative stress and hepatic steatosis in the progression of chronic hepatitis C. J Hepatol 2008; 48: 399-406.

[73] Alvano E, Mottaran E, Vidali M, et al. Immune response towards lipid peroxidation products as a predictor of progression of nonalcoholic fatty liver disease to advanced fibrosis. Gut 2005; 54 : 987-93.

[74] Himoto T, Tani J, Miyoshi H, et al. Investigation of the factors associated with circulating soluble CD36 levels in patients with HCV-related chronic liver disease. Diabetol Metab Syndr 2013; Epub.

[75] Himoto T , Yoneyama H, Deguchi A, et al. Relationship between the production of autoantibodies to oxidized low-density lipoprotein and hepatic steatosis in patients with chronic hepatitis C. Exp Ther Med 2011; 1: 663-8.

[76] Peters MJ, van Halm VP, Nurmohamed MT, et al. Relations between autoantibodies against oxidized low-density lipoprotein, inflammation, subclinical atherosclerosis, and cardiovascular disease in rheumatoid arthritis. J Rheumatol 2008; 35: 1495-9.

[77] Ishizaka N, Ishizaka Y, Takahashi E, et al. Association between hepatitis C virus seropositivity, carotid-artery plaque, and intimamedia thicking. Lancet 2002; 359: 133-5.

[78] Ikeda Y, Toda G, Hashimoto N, et al. Antibody to superoxide dismutase, autoimmune hepatitis, and antibody tests for hepatitis $\mathrm{C}$ virus. Lancet 1990; 335: 1345-6.
[79] Himoto T, Yoneyama H, Kurokohchi K, et al. Clinical relevance of antibodies to cardiolipin in patients with chronic hepatitis C. J Clin Lab Anal 2012; 26: 342-8.

[80] Chen KC, Cahill DS, Kasai H, et al. 8-Hydroxyguanine, an abundant form of oxidative DNA damage, causes G-T and A-C substitutions. J Biol Chem 1992; 267: 166-72.

[81] Leroy V, Arvieux J, Jacob MC, et al. Prevalence and significance of anticardiolipin, anti- $\beta 2$ glycoprotein I and anti-prothrombin antibodies in chronic hepatitis C. Br J Haematol 1998; 101: 468-74.

[82] Dalekos GN, Kistis KG, Boumba DS, et al. Increased incidence of anti-cardiolipin antibodies in patients with hepatitis $\mathrm{C}$ is not associated with aetiopathogenetic link to anti-phospholipid syndrome. Eur J Gastroenterol Hepatol 2000; 12: 67-74

[83] Ordi-Ros J, Villarreal J, Monegal F, et al. Anticardiolipin antibodies in patients with chronic hepatitis $\mathrm{C}$ virus infection: characterization in relation to antiphospholipid syndrome. Clin Diag Lab Immunol 2000; 7: 241-4.

[84] Harada M, Fujisawa Y, Sakisaka S, et al. High prevalence of anticardiolipin antibodies in hepatitis $\mathrm{C}$ virus infection: lack of effects on thrombocytopenia and thrombotic complications. J Gastroenterol 2000; 35: 272-7.

[85] Munoz-Rodriguez FJ, Tässies D, Font J, et al. Prevalence of hepatitis $\mathrm{C}$ virus infection in patients with antiphospholipid syndrome. $\mathrm{J}$ Hepatol 1999; 30: 770-3.

[86] Preito J, Yuste JR, Beloqui O, et al. Anticardiolipin antibodies in chronic hepatitis C: Implication of hepatitis C virus as cause of the antiphospholilid syndrome. Hepatology 1996; 23: 199-204.

[87] Nagao Y, Tsubone K, Kimura R, et al. High prevalence of anticardiolipin antibodies in patients with HCV-associated oral lichen planus. Int J Mol Med 2002; 9: 293-7.

[88] Sthoeger ZM, Fogel M, Smirov A, et al. Anticardiolipin autoantibodies in serum samples and cryoglobulins of patients with chronic hepatitis C infection. Ann Rheum Dis 2000; 59: 483-6.

[89] Liaskos C, Rigopoulou E, Zachou K, et al. Prevalence and clinical significance of anticardiolipin antibodies in patients with type 1 autoimmune hepatitis. J Autoimmun 2005; 24: 251-60.

[90] Zachou K, Liaskos C, Rigopoulou E, et al. Presence of high avidity anticardiolipin antinodies in patients with autoimmune cholestatic liver diseases. Clin Immunol 2006; 119: 203-12.

[91] Gonzalez FJ. Role of cytochrome p450 in chemical toxicity and oxidative stress: studies with CYP2E1. Mutat Res 2005; 459: 10110.

[92] Weltan MD, Farrell GC, Hall P, et al. Hepatic cytochrome p450 2E1 is increased in patients with nonalcoholic steatohepatitis. Hepatology 1998; 27: 128-33.

[93] Gochee PA, Jonsson JR, Clouston AD, et al. Steatosis in chronic hepatitis $\mathrm{C}$ : association with increased messenger RNA expression of collagen I, tumor necrosis factor- $\alpha$ and cytochrome p4502E1. J Gastroenterol Hepatol 2003; 18: 386-92.

[94] Obermayer-Straub P, Strassburg CP, Manns MP. Target proteins in human autoimmunity: cytochrome $\mathrm{p} 450$ and UDPglucuronosyltransferase. Can J Gastroenterol 2000; 14: 429-39.

[95] Lytton SD, Hellander A, Zhang-Gouillon ZQ, et al. Autoantibodies against cytochrome p450 2E1 and p450 3A in alcoholics. Mol Pharmacol 1999; 55: 223-33.

[96] Vidali M, Stewart SF, Rolla R, et al. Genetic and epigenetic factors in autoimmune reactions toward cytochrome p4502E1 in alcoholic liver disease. Hepatology 2003; 37: 410-9.

[97] Miyakawa H, Kitazawa E, Kikuchi K, et al. Immunoreactivity to various human chtochrome $\mathrm{p} 450$ proteins of sera from patients with autoimmune hepatitis, chronic hepatitis $\mathrm{C}$, and chronic hepatitis $\mathrm{C}$. Autoimmunity 2000; 33: 23-32

[98] Mizutami T, Shinoda M, Tanaka Y, et al. Autoantibodies against CYP2D6 and other drug-metabolizing enzymes in autoimmune hepatitis type 2. Drug Metab Rev 2005; 1: 235-52.

[99] Shinoda M, Tanaka Y, Kuno T, et al. High levels of autoantibodies against drug-metabolizing enzymes in SLA/LP-positive AIH-1 sera. Autoimmunity 2004; 37: 473-80

[100] Manns MP, Griffin KJ, Sullivan K, et al. LKM-1 autoantibodies recognize a short linear sequence in P450IID6, a cytochrome $\mathrm{p}-450$ monoovygenase. J Clin Invest 1991; 88: 1370-78.

[101] Njoku DB, Mellerson JL, Talor MV, et al. Role of CYP2E1 immunoglobulin G4 subclass antibodies and complement in pathogenesis of idiosyncratic drug-induced hepatitis. Clin Vaccine Immunol 2006; 13: 258-65. 
[102] Vidali M, Occhino G, Ivaldi A, et al. Detection of auto-antibodies against cytochrome p4502E1 (CYP2E1) in chronic hepatitis C. J Hepatol 2007; 46: 605-12.

[103] Sutti S, Vidali M, Mombello C, et al. Breaking self-torelance toward cytochrome p4502E1 (CYP2E1) in chronic hepatitis C: possible role for molecular mimicry. J Hepatol 2010; 53: 431-8.

[104] Himoto T, Nishioka M. Autoantibodies in hepatitis C virus-related chronic liver disease. Hepat Mon 2008; 8: 295-303.

[105] Miyata M, Kogure A, Sato H, et al. Detection of antibodies to 65 $\mathrm{KD}$ heat shock protein and to human superoxide dismutase in autoimmune hepatitis-molecular mimicry between $65 \mathrm{KD}$ heat shoch protein and superoxide dismutase. Clin Rheumatol 1995; 14: 673-7.

[106] Shingai R, Maeda T, Onishi S, Yamamoto Y. Autoantibodies against $70 \mathrm{KD}$ heat shock protein in patients with autoimmune liver diseases. J Hepatol 1995; 23: 382-90.

[107] Fukuda Y, Yotsuyanagi H, Ooka S, et al. Identification of a new autoantibody in patients with chronic hepatitis. Hum Immunol 2004; 65: 1530-8.

[108] Chumpitazi BF, Bouillet L, Drouet MT, et al. Biological autoimmunity screening in hepatitis C patients by anti-HepG2 lysate and anti-heat shock protein 70.1 autoantibodies. Eur J Clin Microbiol Infect Dis 2009; 28: 137-46.

(C) Himoto et al.; Licensee Bentham Open.

This is an open access article licensed under the terms of the Creative Commons Attribution Non-Commercial License (http://creativecommons.org/licenses/by-nc/3.0/) which permits unrestricted, non-commercial use, distribution and reproduction in any medium, provided the work is properly cited. 